\title{
The Olympic Healthcare Legacy: A Study to Investigate the Perceptions of Relevant Stakeholders to See How the 2012 Olympics Have Affected the Health and Wellbeing of Children in East London by Use of Semi-structured Interviews
}

\author{
Robin Chatterjee $^{1,2, *}$, Stephanie Hemmings ${ }^{1}$ \\ ${ }^{1}$ Sports \& Exercise Medicine Department, Queen Mary University of London, London, E1 4NS, UK \\ ${ }^{2}$ Department of Sports \& Exercise Medicine, Homerton University Hospital, London, E9 6SR, UK \\ *Corresponding author: robinchatterjee1@yahoo.co.uk
}

\begin{abstract}
The six London Boroughs hosting the Games published plans for legacy in the Strategic Regeneration Framework (SRF), where their determination to have parity with the rest of London in various aspects of life including healthcare in children were outlined. There is a paucity of evidence to support the notion that hosting an Olympic games leads to an increase in participation in physical or sporting activities for host countries with also little evidence to suggest other health benefits. To date no research has been conducted to see what the perceptions of stakeholders involved in the healthcare of younger children in East London are, in terms of what healthcare legacy has been left from the 2012 Games. The key objectives were to determine what relevant stakeholders in the care of primary school aged children in the London Borough of Tower Hamlets understood by the term 'healthcare legacy', and to assess their views on the impact of the Olympics on the children and to provide recommendations on how the health and well being of the children may be improved. A qualitative semi-structured interview study design was used. The Framework Method was used to analyse results. 14 stakeholders (GPs, teachers, paediatric community nurses, councillors, youth centre worker) were interviewed and 10 themes were identified: general awareness of healthcare legacy, pre-Olympic status, funding, education, diet, non-tangible effects of the Olympics, Exercise, Social support, local regeneration and further recommendations. The investigation suggested that the Games did emanate a healthcare legacy of sorts. However the effects were largely transient. The multicultural and low socioeconomic nature of Tower Hamlets has made it difficult to establish a legacy. Future recommendations include education of both parents and children on the benefits of a healthy lifestyle.
\end{abstract}

Keywords: Olympic, healthcare, legacy, diet, exercise, East London

Cite This Article: Robin Chatterjee, and Stephanie Hemmings, "The Olympic Healthcare Legacy: A Study to Investigate the Perceptions of Relevant Stakeholders to See How the 2012 Olympics Have Affected the Health and Wellbeing of Children in East London by Use of Semi-structured Interviews.” American Journal of Sports Science and Medicine, vol. 6, no. 2 (2018): 60-66. doi: 10.12691/ajssm-6-2-4.

\section{Introduction}

One of the key factors in London being awarded the Olympics was it's potential to leave a 'lasting legacy'. [1] It was thought that the hype that accompanies the Games would herald a renaissance in grass root participation in sports and a positive shift in attitude. [1]

A number of 'lasting legacies' were formalised by the government of the time to ensure that the Games did actually leave a long-term beneficial effect on the local community. [2,3,4]

Amongst the different legacies that the Government and the British Olympic Association (BOA) promised were a healthcare legacy and a regeneration of the East End of
London. [2] It was hoped that the sporting achievements in today's athletes would lead to an improvement in the health and fitness of tomorrow's children. Indeed the six London Boroughs hosting the Games published plans for legacy in the Strategic Regeneration Framework (SRF), where their determination to have parity with the rest of London in various aspects of life including healthcare in children were outlined [5].

Childhood obesity and inactivity are major issues in our society today, which can lead to long-term adverse health consequences [6,7]. In the United Kingdom (UK), 23\% of children aged $4-5$ and $34 \%$ of those aged $10-11$ are overweight or obese [8].

Physical inactivity is a greater cause of mortality than smoking $[9,10]$. Physical activity levels are however the most prevalent modifiable risk factor for chronic 
disease [11]. Studies have shown that although there are many factors responsible for inactivity and obesity, even a modest school effect has the potential to have a substantial impact on children's weight status at a population level. $[12,13]$ Schools and physical education teachers in particular are in a unique position to promote health and fitness and the Olympics provided an opportunity to reaffirm their importance [14].

The original tender document for the London bid (which the SRF was based on) included chapters on improvement of healthy living and reduction of inequalities in the local population; this would be as a result of actual legislative and fiscal policies as well as more indirect effects such as the 'demonstration effect' and the 'festival effect' [15]. The demonstration effect was the term used to describe the process by which people are inspired by elite sport, sports people and sports events to participate themselves [16]. The festival effect described the desire to participate in physical activity as a result of celebration and camaraderie contributing to the feeling that an event is bigger than and beyond the sporting occasion itself [17].

However a recent overview of systematic reviews reported that there was a paucity of evidence to support the notion that hosting an Olympic games leads to an increase in participation in physical or sporting activities for host countries with also little evidence to suggest other health benefits [18]. The study reported that there were only two systematic reviews of note: (1) McCartney et al (2010), which was a review of literature published between 1978 and 2008, found insufficient evidence to support or refute any health or socioeconomic impacts from major multisport events [19]; (2) Weed et al (2009) concluded that communities that were not engaged with the 2012 games were likely to be beyond the reach of any legacy and that the key to providing a physical activity legacy was to promote the festival effect and to promote exercise through community events or programmes [20]. In addition a recent qualitative study postulated that the London Olympics have not inspired any change in the physical activity of individuals [21].

Various different legacies have been investigated since the end of the London Olympics. The ORiEL study has investigated the thoughts of adolescents and parents on how the Olympics have affected them [22]. A study looking into the effects of the Vancouver Winter Olympics on local children found that the games had no measurable impact on objectively measured physical activity or increased sports participation [23]. To date no research has been conducted to see what the perceptions of stakeholders involved in the healthcare of younger children in East London are, in terms of what healthcare legacy has been left from the 2012 Games.

The objectives of this study were:

1. To determine what relevant stakeholders in the care of primary school aged children in the London Borough of Tower Hamlets (one of the six boroughs that contributed to the SRF) understood by the term 'healthcare legacy' [5].

2. To assess the views of the stakeholders on what tangible and non-tangible impact the 2012 Olympic games have had on the healthcare of the children that they care for.

3. To provide recommendations on how the health and well being of primary school children in the London Borough of Tower Hamlets could be improved.

\section{Materials and Methods}

\subsection{Design}

Given the aims of this study, a qualitative study using semi-structured interviews was used to harvest data. This approach is commonly used when the data needed is based upon complex behaviours, needs, systems and cultures [24]. This method allowed a range of views to be taken using a flexible approach with an evolving nature of questioning based on interviewee response [24].

\subsection{Participants}

Relevant stakeholders in the healthcare of children aged between 5-11 years old in the London Borough were selected for interview. A sampling frame was used to purposefully recruit participants in order to optimise external validity and appropriately represent the population being studied (see Table 1).

\subsection{Ethics Approval}

Ethical approval was obtained from Queen Mary University of London (QMUL) Research Committee in February 2015. Research Ethics Committee (REC) approval was granted by North Central London Research Consortium (NoCLoR) in April 2015. NHS Research and development (R\&D) approval was obtained from Barts Health NHS Trust in June 2015.

Table 1. Sampling Frame with Inclusion and Exclusion Criteria

\begin{tabular}{|c|c|c|c|c|}
\hline Stakeholder & Inclusion Criteria & Exclusion Criteria & Number contacted & $\begin{array}{l}\text { Number } \\
\text { Interviewed }\end{array}$ \\
\hline $\begin{array}{l}\text { General } \\
\text { Practitioners }\end{array}$ & \multirow{5}{*}{$\begin{array}{l}\text { The subject must work in the London Borough of } \\
\text { Tower Hamlets } \\
\text { They must be actively working with, treating or } \\
\text { involved in the healthcare management of primary } \\
\text { school aged (5-11 year old) children in the borough } \\
\text { They must have worked with the population being } \\
\text { studied for at least } 2 \text { years prior to the advent of the } \\
\text { Olympics (from 2010) } \\
\text { They must work for the public sector only } \\
\text { If a GP then must be a partner or salaried doctor. } \\
\text { If a teacher then must be either a head teacher or PE } \\
\text { teacher. }\end{array}$} & \multirow{5}{*}{$\begin{array}{l}\text { The interviewee must have } \\
\text { no direct affiliation with } \\
\text { the BOA, government or } \\
\text { Olympic Games } \\
\text { They must not gain } \\
\text { financially from any } \\
\text { intervention that may have } \\
\text { benefitted the healthcare of } \\
\text { the children }\end{array}$} & $\begin{array}{l}36 \text { practices (110 } \\
\text { GPs) }\end{array}$ & 4 \\
\hline Teachers & & & $\begin{array}{l}60 \text { schools (60 head } \\
\text { teachers and } 48 \mathrm{PE} \\
\text { teachers) }\end{array}$ & $\begin{array}{l}6 \\
\text { (2 PE teachers and } \\
4 \text { head teachers) } \\
\end{array}$ \\
\hline $\begin{array}{l}\text { Local } \\
\text { Councillors }\end{array}$ & & & 12 & ( \\
\hline $\begin{array}{l}\text { Youth Centre } \\
\text { Worker }\end{array}$ & & & 8 & 1 \\
\hline $\begin{array}{l}\text { Paediatric } \\
\text { Nurse } \\
\text { Practitioners } \\
\end{array}$ & & & 10 & 2 \\
\hline
\end{tabular}




\subsection{Data Collection}

Using the sampling frame prospective patients were contacted by e-mail. 60 primary schools in the London Borough of Tower Hamlets, were identified from the website of the Local Authority. [25] Local councillors involved in child health and welfare and council accredited charity workers for young children were also obtained from the same site. 36 general practices were identified from the Tower Hamlets Clinical Commissioning Group (CCG) website. [26] 10 community paediatric nurses were identified from the same website. Prospective participants who were identified according to the inclusion and exclusion criteria were forwarded an opening email, participant information sheet and consent form. Recruitment was without coercion. The consent form was required to be signed prior to interview.

Each interview was semi-structured in nature, face-to-face, conducted in a location suitable for the participant. Internal validation was conducted in a number of ways. (i) Use of a topic guide to fully explore the views of each participant and ensure a certain uniformity of questions (see Table 2); (ii) the study author was always the interviewer; (iii) Interviews were continued until data saturation occurred; (iv) They were all conducted within a two-week period and recorded in order to improve recall and accuracy during analysis. All interviewees were guaranteed anonymity, in order to allow individuals to speak freely, especially if they wished to express negative views.

\section{Table 2. Interview topic guide}

$$
\begin{aligned}
& \text { - General Awareness of the Healthcare Legacy } \\
& \text { - Pre-Olympic Status } \\
& \text { - Funding } \\
& \text { - Legislation and direction from the Local Education \& Health } \\
& \text { - Education } \\
& \text { - Diet } \\
& \text { - Exercise } \\
& \text { - Non-tangible Impact of the Olympics }
\end{aligned}
$$

\subsection{Analysis}

All interviews were fully transcribed before a thematic analysis was performed using the Framework Method $[27,28]$. This method involved five stages:

I. Familiarisation of the transcription

II. Development of a theoretical framework: Important recurrent themes were identified and then subdivided into subthemes and microthemes. This took place through an internal process of reflection and compulsory written reflection. Internal validation took place at this stage by re-reading all transcripts to identify all possible themes.

III. Indexing and charting: Themes were coded based on similarities and differences between initial themes which allowed refinement of the initial themes to more accurately reflect the data. These themes and subthemes were then charted to allow clear identification of emerging concepts.
IV. Summarisation of data: this was done to make the data simple and easy to interpret.

V. Mapping and interpreting: Themes and subthemes were compared and contrasted to allow the initial objectives of the study to be answered. A completed framework was then tabulated. Respondent validation was then conducted by presenting the framework to a GP and a teacher who had taken part in the study. They provided feedback and any new suggestions were further included in the final results.

Respondent validation was performed by allowing two of the participants (a teacher and a GP) to read through their own transcriptions to ensure that the nuances of their interviews had been captured.

\subsection{Ethics Approval}

Ethical approval was obtained from Queen Mary University of London (QMUL) Research Committee in February 2015. REC approval was granted by NoCLoR in April 2015. NHS R\&D approval was obtained from Barts Health NHS Trust in June 2015.

\section{Results}

A total of 248 individuals were contacted with only 14 (5\%) recruited and interviewed; this included $2 \mathrm{PE}$ teachers, 4 head teachers, 4 GPs, 1 local councillor, 1 youth centre worker and 2 community paediatric nurses (see Table 1). Interviews ranged in length between 10 minutes and 58 minutes with a mean time of 27 minutes. 31 subthemes were identified which were grouped into 10 themes (see Table 3).

\subsection{General Awareness of Healthcare Legacy}

Most of the participants had heard of the term 'healthcare legacy' though not in an official capacity. They were aware of it through mass media rather than any direction from local government. Their ideas on what it meant varied from meaning an increase in funding due to the Olympics, promotion of health and well being to an improvement in infrastructure.

In terms of knowledge of any specific commitment made by the London Borough of Tower Hamlets towards the health and well being of the local population, most were unaware of such a thing. Nobody had heard of the Strategic Regeneration Framework and there was no knowledge of any formal documentation detailing what plans the six involved boroughs had to implement a healthcare legacy. Those who thought that they were aware of a commitment, in fact did not offer much detail, but instead offered speculative conjecture.

\subsection{Pre-Olympic Status}

Diet and exercise were an afterthought for both the children and their parents prior to the Olympics. With a high percentage of children originating from a South East Asian background, academia was deemed more important by the parents than sporting achievement. Some interviewees stated that being larger in size was actually desirable trait 
in some children and their families as it was considered a sign of prosperity in their culture.

Although most stakeholders felt that facilities and funding prior to the Olympics was poor, some did observe that schools were still afforded a reasonable budget for PE and that finances were available but maybe not spent in the correct areas.

\subsection{Funding}

The majority of stakeholders felt that funding post-Olympics had remained poor. Some thought that there was a temporary increase immediately after the Games but with the commencement of the Government's commitment to austerity measures that any increase had been reduced in recent times. Those who had felt the impact of an increase in funding because of the Olympics generally thought that the healthcare of the children was being addressed with the commencement of free fruit and milk and breakfast at school. Obesity clinics for all ages had also been introduced as a result of an increase in postgames funding. One $\mathrm{PE}$ teacher felt that since the
Olympics, his departmental budget had significantly increased and as he was given the responsibility of distributing the funds he felt that it had been allocated adequately. Suggestions for where funds could be distributed to further help child healthcare included afterschool schemes, language classes for parents and obesity prevention (as opposed to treatment) services.

\subsection{Education}

Some schools had home economic classes for primary school children and all schools in the area had at least one compulsory PE lesson per week. However it was felt that more was needed to overcome cultural beliefs and traditions such as the consumption of high fat foods and discouragement of girls to exercise. Stakeholders believed that this could be achieved through education of parents more than the children. They felt that a multi-organisational approach (i.e. both health and education services) was needed to accomplish this. Most felt that there was no leadership or guidance from their respective local authorities with regards to this.

Table 3. Abbreviated Framework to Show Themes, Subthemes and Illustrative Quotes Established From Semi-Structured Interviews Together with Findings

\begin{tabular}{|c|c|c|}
\hline Themes & Subthemes & Illustrative Quotes \\
\hline $\begin{array}{l}\text { General } \\
\text { awareness of } \\
\text { healthcare legacy }\end{array}$ & $\begin{array}{l}\text { - Understanding of the term healthcare legacy } \\
\text { - Knowledge of specific commitments made to London } \\
\text { Borough of Tower Hamlets in terms of health and well-being } \\
\text { as a result of Olympics }\end{array}$ & $\begin{array}{l}\text { '....to promote health and fitness in anyone.....' } \\
\text { ‘....rejuvenating a deprived area and getting pupils more } \\
\text { involved in sports. I don’t necessarily think that happened’ }\end{array}$ \\
\hline $\begin{array}{l}\text { Pre-Olympic } \\
\text { status }\end{array}$ & $\begin{array}{l}\text { - Attitudes } \\
\text { - Facilities/Amenities/Funding }\end{array}$ & $\begin{array}{l}\text { '... it's a multi-ethnic society and they all have different diets } \\
\text { which can be very unhealthy... emphasis isn't on health } \\
\text { promotion...' }\end{array}$ \\
\hline Funding & $\begin{array}{l}\text { - Current levels acceptable } \\
\text { - Suggestions of where funds should be allocated } \\
\text { - Current levels unacceptable } \\
\text { - Awareness of any increase in funding aimed at improving the } \\
\text { health and well-being of the children since the Olympics }\end{array}$ & $\begin{array}{l}\text { 'following the Olympics... a burst of increased funding but I } \\
\text { think the funding isn't there any more' } \\
\text { '...there was increased funding for these schools..that's been } \\
\text { reduced again since the austerity started..' }\end{array}$ \\
\hline Education & $\begin{array}{l}\text { - Educating Children } \\
\text { - Educating Parents } \\
\text { - Direction from local education or health authorities }\end{array}$ & $\begin{array}{l}\text { 'Allocate some funding to educating parents in the local } \\
\text { borough, making them aware of the benefits of eating } \\
\text { healthy... encouraging their children to partake in sports, not } \\
\text { just boys but both girls' }\end{array}$ \\
\hline Diet & $\begin{array}{l}\text { - School } \\
\text { - Cultural Influences } \\
\text { - Environmental Influences } \\
\text { - Socioeconomic Influences }\end{array}$ & $\begin{array}{l}\text { '...at home parents feed their children..food that's high in } \\
\text { cholesterol, high in fats, ghee for instance.... lot of these } \\
\text { parents they just don't have the education....it's more about } \\
\text { just cooking what they are used to cooking' }\end{array}$ \\
\hline $\begin{array}{l}\text { Non tangible } \\
\text { effects of } \\
\text { Olympics }\end{array}$ & $\begin{array}{l}\text { - Demonstration Effect } \\
\text { - Festival Effect } \\
\text { - No effect }\end{array}$ & $\begin{array}{l}\text { '...not many local children actually did go to see the } \\
\text { Olympics' } \\
\text { '...they felt less British and they weren't really that interested } \\
\text { in the Olympics' }\end{array}$ \\
\hline Exercise & $\begin{array}{l}\text { - Type of sport preferred } \\
\text { - Exercise at school } \\
\text { - Exercise outside school } \\
\text { - Socioeconomic influences }\end{array}$ & $\begin{array}{l}\text { 'They'd just do football because it was a lot more accessible } \\
\text { to these kids' } \\
\text { 'So, the PE time has been cut in the last decade. So, children } \\
\text { are spending less time active in class' }\end{array}$ \\
\hline $\begin{array}{l}\text { Local } \\
\text { Regeneration }\end{array}$ & $\begin{array}{l}\text { - Encourage out-of-school hours exercise } \\
\text { - No effect }\end{array}$ & $\begin{array}{l}\text { '...cycle lanes... it's a lot safer to cycle and there's parks and } \\
\text { green areas where they can go and play and do things after } \\
\text { school' }\end{array}$ \\
\hline $\begin{array}{l}\text { Social support as } \\
\text { a result of the } \\
\text { Olympics }\end{array}$ & - Out of school help & $\begin{array}{l}\text { 'there needs to be... after-hours facility for the kids so that } \\
\text { they can...participate in...sports so that if the parents are } \\
\text { working late then they have something that's positive and fun } \\
\text { to do' }\end{array}$ \\
\hline $\begin{array}{l}\text { Further } \\
\text { Recommendations }\end{array}$ & $\begin{array}{l}\text { - Education } \\
\text { - Funding } \\
\text { - Diet } \\
\text { - Addressing deprivation } \\
\text { - Exercise } \\
\text { - School }\end{array}$ & $\begin{array}{l}\text { '...you need to try and educate them on the importance of } \\
\text { fresh fruit and veg and a balanced diet...I would try to explain } \\
\text { about parents who really don't understand about the } \\
\text { importance of health and education......Lots of leaflets... health } \\
\text { promotion, adverts...' }\end{array}$ \\
\hline
\end{tabular}




\subsection{Diet}

The large South East Asian diaspora in the region together with higher levels of deprivation meant that most diets consisted of high fat, high cholesterol curries at home with fried chicken and chips considered the take away of choice. These foods were considered tastier and cheaper than fruit or vegetables or other alternate diets. Although free fruit, milk and breakfasts were being offered at school since the Olympics, stakeholders felt that long standing beliefs held on diet still existed.

\subsection{Non-tangible Effects of the Olympic Games}

Most stakeholders felt that that the Olympics provided both a demonstration and a festival effect on the local children. This effect was thought to be mainly transient with declining influence as time lapsed since the games. However, it was felt that some children of Bangladeshi origin did not experience either of these effects as they were less likely to feel 'British' and so were not overly influenced by the success experienced by Team GB. In addition many children and their families were priced out of going to any of the Olympics, which contributed to an overall greater feeling of disenfranchisement from British society. Longer lasting effects included the introduction of new sports to schools such as table tennis, which occurred due to interest being raised from the Games.

\subsection{Exercise}

Those children who were interested in sport prior to the Games were more likely to be influenced by the Olympics and thus the healthcare legacy had a greater impact on them. Cricket and football appeared to be the sports of choice for the children despite introduction to new sports via the Olympics. Only one compulsory session of $\mathrm{PE}$ occurred per week and this was not increased after the Olympics. In fact PE time was cut in some schools because of a cut in funding.

\subsection{Local Regeneration}

Though more parklands and cycle lanes were created, it was felt that these were more likely to benefit older children and adults rather than the primary school aged children. The actual Olympic Park and its associated sites were also deemed too expensive for the local children to use.

\subsection{Social Support as a Result of the Olympics}

Only two stakeholders were aware of any additional social services that were available post-Olympics. These services were pre and post school clubs and new youth centres for younger children. Most of the participants felt that more social support was needed for both parents and children to allow them to have greater finances to buy healthier foodstuffs or join gyms and clubs and also to have more time to spend as a family; hopefully participating in exercise.

\subsection{Further Recommendations}

The participants identified a diverse range of recommendations. This included increased education for the parents as well as their children. Education involved improved language skills, the challenge of cultural beliefs such as notions that girls should not exercise or that being overweight is a desirable quality. It should be impressed upon the parents that physical activity is as important as academic and that the two actually go hand in hand.

\section{Discussion}

This study explored the perceptions of relevant stakeholders to see how the 2012 Olympics affected the health and wellbeing of primary school aged children (aged 5-11 years) in the London Borough of Tower Hamlets by use of semi-structured interviews. The participants consisted of GPs, PE teachers, head teachers, paediatric community nurses, 1 youth centre worker and 1 local councillor. The investigation was conducted because Tower Hamlets was one of six London boroughs, which contributed towards a document called the Strategic Regeneration Framework. This document stated that amongst other things, the children in the locality would have a healthcare legacy bestowed upon them as a result of the Olympics. A topic guide was used to highlight key themes to indicate if a healthcare legacy was perceived to have occurred successfully.

The main findings of the study were that stakeholders thought that the Olympics had a minimal transient effect on the children. The main factors identified as reasons why the Olympics did not have more of an effect were the large local Bangladeshi population, the high level of deprivation and poor education.

$32 \%$ of the local population was of Bangladeshi descent. [29] Stakeholders reported that this population somewhat felt disenfranchised from mainstream British society and so the Olympics had less of a festival effect than on other communities. Culturally parents from this community tended to encourage their children to focus more on academic success rather than sporting, as it was considered a more realistic route for future prosperity, and this negated a demonstration effect. High fat and high cholesterol diets were also a norm in this community and this contributed to high obesity levels in children. Poor spoken English and deprivation contributed to a diminished festival effect. A lack of exercise was found to be a greater problem in the young girls rather than boys, as they were likely told by their parents that they should not expose skin (i.e. t-shirt, shorts, swimming costumes) for reasons of modesty or merely that it was not acceptable for a girl to exercise.

Table 4. Ethnic diversity in London Borough of Tower Hamlets [29]

\begin{tabular}{|l|c|c|c|}
\hline Race & Tower Hamlets \% & London \% & England \% \\
\hline White & 45.2 & 59.8 & 85.4 \\
\hline Mixed & 4.1 & 5.0 & 2.3 \\
\hline Asian or Asian British & 41.1 & 18.5 & 7.8 \\
\hline Black or Black British & 7.3 & 13.3 & 3.5 \\
\hline Other Ethnic Group & 2.3 & 3.4 & 1.0 \\
\hline
\end{tabular}


Tower Hamlets has the highest rate of income poverty across all local authorities in England and Wales and double the national average (22\%). [30] This level of deprivation contributed towards the dietary choices of the local children and their families. Dining in one of the many fried chicken and chip shops was considered a cheaper option to eating fresh fruit and vegetables. Local children were unable to actually see any of the Olympic events even though they were occurring on their doorstep, as tickets were unaffordable. Minority sports that captured the public imagination during the games, such as cycling or rowing did not have much of an impact in this community, as they again were considered financially inaccessible. The Cricket World Cup had more of a demonstration effect than the Olympics. Premier League Football also had a greater impact on the children than the Olympics due to the constant media coverage and affordability and simplicity of playing football at school or parks.

Positive effects of the Olympics included free fruit, milk and breakfast at school, to ensure at least some nutrients were being consumed on a daily basis. At least 1 session of PE was compulsory in schools, though this appears to have also occurred pre-Olympics. Anti-obesity clinics and MEND (mind, exercise, nutrition, do-it) childhood obesity programmes have also been afforded increased relevance and funding since the Olympics. [31] Local regeneration was found to have increased parklands and cycling lanes but the impact of this on younger children was disputed.

In terms of fulfilling the objectives of the study, the investigation concluded that:

I. Most stakeholders had heard of the term 'healthcare legacy' but not on a formal basis. They had wildly varying interpretations as to what this encompassed but generally everyone agreed that it had an element of aspiration to improve the well-being of the local children.

II. The games did indeed have a tangible and nontangible impact on the local children (as detailed above), though this effect was short-lived. Funding appeared to have decreased with the Government's agenda of austerity thus hastening the speed with which the impact dwindled.

III. In evaluating the findings from the study, a summary of the recommendations made to improve the health and well-being of the children include:

\subsection{Limitations}

Despite attempting to recruit a large number of subjects the sample was small. Thematic saturation may have been achieved because of a lack of diversity among the sample. Given the high rates of refusal to participate, recruitment bias may have been a factor, as only the more opinionated individuals were likely to participate. More teachers and GPs were interviewed than other professions, thus skewing the themes formed as the same topics would be likely to arise. The study only took place in one of the six boroughs involved in the SRF and so results from this study may not be applicable to the others. There were no other interviewers or analysts apart from the main author. This may have limited the internal validity of the study as no other researcher could check participant's understanding of the questions or re-read transcripts to optimise familiarisation. Triangulation using different interviewers and analysts would have been preferable. As no similar study has been performed, it was difficult to compare results with previous research thus limiting ability to confirm trends identified.

\section{Conclusion}

This was the first study to look at the perceptions of grass-root workers on what healthcare legacy the Olympics had bestowed on young children in one of the boroughs that hosted the games. 10 themes were identified: general awareness of healthcare legacy, pre-Olympic status, funding, education, diet, non-tangible effects of the Olympics, Exercise, Social support, local regeneration and further recommendations. The investigation suggested that the Games did emanate a healthcare legacy of sorts. However the effects were largely transient. The specific healthcare needs of the local population appear not to have been considered prior to the conception of the idea of the healthcare legacy and this has most likely contributed to the perceived lack of full success of the healthcare legacy.

Further studies that can be conducted include a qualitative study in the other boroughs to see if trends are similar in each. An audit of how the finances in the borough were distributed post-Olympics could also be done to see if there is any correlation between the perceptions of stakeholders and distribution of funds.

\section{Acknowledgements}

The author would like to thank all participants of this study and also research facilitators at North Central London Research Consortium (NoCLoR) research support service for their assistance in obtaining Research Ethics Committee (REC) and Research and development (R\&D) approval.

\section{Statement of Competing Interests}

The authors declare that they have no financial or nonfinancial competing interests.

\section{List of Abbreviations}

\author{
BOA: British Olympic Association \\ GP: General Practitioner \\ NHS: National Health Service \\ NoCLoR: North Central London Research Consortium \\ ORiEL: Olympic Regeneration in East London \\ PE: Physical education \\ QMUL: Queen Mary University of London \\ R\&D: Research and development \\ REC: Research Ethics Committee \\ SRF: Strategic Regeneration Framework \\ UK: United Kingdom
}




\section{References}

[1] Chatterjee R. A lasting legacy: clinical commissioning groups and sport medicine. Br J Gen Pract. 2014 Mar; 64(620): 141.

[2] gov.uk. Creating a lasting legacy from 2012 Olympic and Paralympic Games. Available from:

https://www.gov.uk/government/policies/creating-a-lastinglegacy-from-the-2012-olympic-and-paralympic-games (last accessed 01/08/15)

[3] gov.uk. Department for culture, media and Sport. Our Promise for 2012. How the UK will benefit from the Olympic and Paralympic Games. Available from:

https://www.gov.uk/government/uploads/system/uploads/attachme nt_data/file/77718/Ourpromise2012Forword.pdf (last accessed 01/08/15).

[4] Seeman T, Chen X. Risk and protective factors for physical functioning in older adults with and without chronic conditions: MacArthur studies of successful aging. J Gerontol B Psychol Sci Soc Sci. 2002 May; 57 (3): 135-44.

[5] Hackney Council: 2012 Games- The Host Boroughs and the Strategic Regeneration Framework. Available from: http://www.hackney.gov.uk/srf.htm (last accessed 01/08/15).

[6] Fox KR. Childhood obesity and the role of physical activity. J R Soc Promot Health. 2004 Jan; 124 (1): 34-9.

[7] Singh AS, Mulder C, Twisk JWR et al. Tracking of childhood overweight into adulthood: a systematic review of the literature. Obes Rev 2008; 9:474-88.

[8] NHS Information Centre for Health and Social Care. National Child Measurement Programme: England, 2011/12 school year, 2012.

[9] Murray CJ, Richards MA, Newton JN et al. UK health performance: findings of the Global Burden of Disease Study 2010. Lancet. 2013 Mar 23; 381(9871): 997-1020.

[10] Chakravarty EF, Hubert HB, Krishnan E et al. Lifestyle risk factors predict disability and death in healthy aging adults. Am J Med. 2012 Feb; 125(2): 190-7.

[11] Wellings K, Datta J, Wilkinson P, Petticrew M. The 2012 Olympics: assessing the public health effect. Lancet 2011: 378: 1193-95.

[12] Langley-Evans SC, Moran VH. Childhood obesity: risk factors, prevention and management. Matern Child Nutr. 2014 Oct; 10(4): 453-5.

[13] Pallan MJ, Adab P, Sitch AJ. Are school physical activity characteristics associated with weight status in primary school children? A multilevel cross-sectional analysis of routine surveillance data. Arch Dis Child. 2014; 99: 135-141.

[14] Lewis K. Pupils' and teachers' experiences of school-based phsycial education: a qualitative study. BMJ Open 2014; 4: e005277.

[15] London 2012. Response to the questionnaire for cities applying to become candidate cities to host the Games of the XXX Olympiad and the Paralympic Games in 2012. Available from: http://www.london2012.com/documents/candidatefiles/questionnaire-response-english.pdf (last accessed 01/08/15).

[16] Weed M, Coren E, Fiore J et al. Developing a physical activity legacy from the London 2012 Olympic and Paralympic Games: a policy-led systematic review. Perspect Public Health 2012 Mar; 132(2): 75-9.
[17] Chalip L. Towards social leverage of sports events. Journal of Sport and Tourism. 2006; 11: 109-27.

[18] Mahtani KR, Protheroe J, Slight SP et al. Can the London 2012 Olympics 'inspire a generation' to do more physical or sporting activities? An overview of systematic reviews. BMJ Open. 2013 Jan 7; 3(1). Pii e002058.

[19] McCartney G, Thomas S, Thompson $\mathrm{H}$ et al. The health and socioeconomic impacts of major multi-sport event events: systematic review (1978-2008). BMJ 2010; 340:c 2369.

[20] Weed M, Coren E, Fiore J et al. A systematic review of the evidence base for developing a physical activity and health legacy from the London 2012 Olympic and Paralympic games. London: Department of Health. 2009. Available from: http://www.london.nhs.uk/webfiles/Independent\%20inquiries/Dev eloping\%20physical\%20activity\%20and\%20health\%20legacy\%2 0-\%20full\%20report.pdf. (last accessed 01/08/15).

[21] Carter RV and Lorenc T. A Qualitative Study into the development of a physical activity legacy from the London 2012 Olympic Games. Health Promot Int 2013 Sept 19 (epub ahead of print).

[22] Smith NR, Clark C, Fahy AE, Tharmaratnam V, Lewis DJ, Thompson C, Renton A, Moore DG, Bhui KS, Taylor SJ, Eldridge S, Petticrew M, Greenhalgh T, Stansfeld SA, Cummins S. The Olympic Regeneration in East London (ORiEL) study: protocol for a prospective controlled quasi-experiment to evaluate the impact of urban regeneration on young people and their families. BMJ Open. 2012 Aug 29; 2(4).

[23] Craig CL, Bauman AE. The impact of the Vancouver Winter Olympics on population level physical activity and sport participation among Canadian children and adolescents: population based study. Int J Behav Nutr Phys Act 2014 Sep 3; 11: 107.

[24] Huberman M and Miles MB. 2002. The qualitative researcher's companion. Sage. p. 307.

[25] Tower Hamlets Council Legislation. Primary Schools in the borough. Available from: http://www.towerhamlets.gov.uk/lgsl/150/17_schools/primary_sch ools1.aspx (last accessed 01/08/15).

[26] Tower Hamlets CCG.GP practices holding membership in the CCG. Available from: http://www.towerhamletsccg.nhs.uk/about/ccg-memberpractices.htm (last accessed 01/08/15).

[27] Gale NK, Heath G, Cameron E, Rashid S, Redwood S. Using the framework method of analysis of qualitative data in multidisciplinary health research. BMC Medical Research Methodology. 2013; 13: 117.

[28] Ward DJ, Furber C, Tierney S et al. Using framework analysis in nursing research: a worked example. J Adv Nurs. 2013; 69(11): 2423-2431.

[29] Ethnicity of Tower hamlets: analysis of 2011 census data. Available from: http://www.towerhamlets.gov.uk/lgnl/community_and_living/boro ugh_profile/research_and_briefings/diversity.aspx (last accessed 01/08/15).

[30] A poverty profile of tower hamlets. Available from: http://www.towerhamlets.gov.uk/lgnl/community_and_living/boro ugh_profile/research_and_briefings/income_and_poverty.aspx (last accessed 01/08/15)

[31] MEND. Available on: http://www.mendcentral.org/ (last accessed 01/08/15). 